\title{
Exploring the Role of Technical Features in Promoting the Intention to Continue Sharing Contents in Social Commerce Platform
}

\author{
Huifen Wang, Haiyan Fang, Qiuhong Tang \\ Department of Business Administration, Jinan University, Guangzhou, China \\ Email: twhf@163.com,joycefanghaiyan@163.com
}

How to cite this paper: Wang, H.F., Fang, H.Y. and Tang, Q.H. (2019) Exploring the Role of Technical Features in Promoting the Intention to Continue Sharing Contents in Social Commerce Platform. Journal of Service Science and Management, 12, 214-233.

https://doi.org/10.4236/jssm.2019.122015

Received: January 17, 2019

Accepted: February 23, 2019

Published: February 26, 2019

Copyright $\odot 2019$ by author(s) and Scientific Research Publishing Inc. This work is licensed under the Creative Commons Attribution International License (CC BY 4.0).

http://creativecommons.org/licenses/by/4.0/

(c) $\underset{\mathrm{EY}}{\mathrm{EP}}$ Open Access

\begin{abstract}
For this paper, we'd like to explore the role of the technical features on the users' continuous intention to share contents in the social commerce platform based on social cognition theory. The social commerce is an emerging e-commerce platform along with the development of social media technology. Compared with traditional e-commerce, user's content sharing has been recognized as the most important resource for the social commerce platform to attract new users as well as help old users make a better purchase decision. Drawing on the literature of the Social Cognition theory, the intention to continue sharing contents, the technical support of social commerce, the author develops a new model to understand the mechanism of the user's intention to continue sharing contents and uses the SEM to test the model. Results show that technical support has a positive influence on the intention to continue sharing content, also increases the level of self-efficacy perception and outcome expectations, which in turn increases users' intention to share contents. Implications, limitations, discussion, and future research directions are discussed at the end of the paper.
\end{abstract}

\section{Keywords}

Social Commerce, Technical Features, Social Cognition Theory, Content Sharing

\section{Introduction}

With the rapid development of Web2.0 and social media technologies, social commerce as a new type of e-commerce development model has emerged. The social e-commerce platform relies on social media and websites to assist in the 
purchase and sale of goods or services through new means such as social interaction users or user-generated content. As an emerging business model, the social commerce is in a period of rapid development, more and more enterprises are beginning to enter social e-commerce, but some new problems are emerging: such as the low level of users' acceptance, usage frequency and the intention to share. It is easy to find that the user's behavioral habits in the social commerce platform remain to be cultivated. The most prominent problem in the social commerce platform is that the vast majority of users are information acquirer, and they rarely or even never share information. The famous "90-9-1 rule" of the online community is also demonstrated in the social commerce platform, it shows that $90 \%$ of users in the social commerce platform are not content contributors, $9 \%$ of users occasionally contribute, also only $1 \%$ of users often contribute [1]. While the user's interaction and stickiness is generated based on the content provider, if the content provider is lacking, other user's interaction and stickiness on the platform will be influenced [2]. Therefore, the social commerce operator is always faced with the problem of how to keep users generate and share content or information continuously and effectively.

Compared with traditional e-commerce, the social commerce platform develops new functions depends on the new technical support, such as personal recommendations and referrals, ratings and reviews, forums and communities and so on. These social techniques give opportunities to consumers to support each other with information exchange and with the content they generate there [3]. Many prior studies have identified a number of factors that influence the users' intention to share information or purchase experience. Despite this progress, a careful review of these studies uncovers that they have missed a factor which is considered highly important to contents sharing-the technical support of social commerce platform. In this regard, objective of our study is to address this gap by exploring the role of technical support in affecting contents-sharing behavior in social commerce platform.

Like other virtual network, the social commerce platform is also with unique social environment features. In the field of sociology, individual cognition has been considered to be the most important factor on user behavior [4]. Social cognitive theory (SCT) is particularly relevant to this study because it can explain human motivation for content sharing behavior as a function of the reciprocal interactions involving behavior, cognition, and social environmental influences. In the present context of social commerce, the potential three interdependent factors are users' content share intention, their assessment of the likely social consequences of the content sharing behavior and their perceived ability to engage in social commerce platform, and the technical features of the social commerce platform.

Therefore, the present study tries to investigate on the role of technical support on self-efficacy, outcome expectations and intention to share information and purchase experience. That is, this paper will answer these questions: 1) Do 
technical features influence users' self-efficacy, outcome expectations and intention to share information? 2) Do users' self-efficacy, outcome expectations influence users' intention to share information? To answer these questions a survey was conducted with Red users in the China.

\section{Literature Review and Theoretical Framework}

\subsection{Social Commerce}

Social commerce is an emerging e-commerce model that along with the development of WEB2.0 and social media technologies. Its concept was first proposed by Jascanu and Nicolau, who defined it as a social network combination based on e-commerce sites and social networking sites and as a bridge between merchants and users for information exchange [5]. In social commerce platform, the customers' online shopping experience will be enhanced by the social functions, sales and purchases of products can be promoted through sharing and interaction between users. Since the research object is Red, which is a social commerce platform based on UGC community. Therefore, this paper defines the social commerce as an environment that creates social interaction by social technology. In this platform, information dissemination and recommendation are character with the user's initiative to generate content, thereby enhancing sharing, interaction and trust between users, assisting users in making suitable purchase decisions, which in turn enhancing users' intention to use social commerce [6].

In the early period of social commerce, some researcher thought it was just a new category or branch of e-commerce. With the social interpersonal interaction presented in social media, social media has gradually become the core platform of social commerce, the difference between social commerce and traditional e-commerce has become increasingly apparent. In a summary, social commerce not only cares for the commodity, but also pays more attention to human factors, establishes users' network relationship, takes advantage of the role of interpersonal influence. Social commerce takes social interpersonal interaction as its core, and conducts business activities based on the social network that has been formed among users.

Users are the key driving forces for the sustainable development of social commerce platforms. Users' participation frequency is the important foundations for value creation of the platform. Thus, the user behavior has always been the most concerned research topic in this theme. Hajli discovered the recommendation/reference, forum/community, rating/comments are attracting users to have interactions as well as generate content on the platform, which will increase the level of trust and the intention to purchase [7]. Bai Y. discussed the influence of social support, seller uncertainty and product uncertainty on consumers' purchasing behavior based on the motivation theory [8]. Hasanov explored the impact of website quality on users' satisfaction, and in turn on customers' online shopping behavior intentions [9]. However, it not difficult to find that most of the studies focused on the intention of customers to buy in 
s-commerce websites, meaning that, transaction behavior was the main focus. While on the other hand, the other customer behavior has become a key concept in the near future. Crossler clearly highlighted that there is a lack in identifying the factors that affect customer engagement intention in s-commerce [10]. Therefore, there is strong need for better understanding of what motivate customers to engage in s-commerce activities, such as generate and share goods information or purchase experience.

\subsection{Technical Features}

Web2.0 technologies and social network sites have changed not only the structure of commerce but also how firms and customers interact in the virtual marketplace. The increasingly growing implementation of these technologies has encouraged meaningful relationships and modified the role of customers in the platform. Today researchers claim that the characteristics of the above social commerce platform is based on its technical features, such as the personalized technical, which is used to support the user's personalized expression or satisfy personal products or service information needs [11]; the interaction technical, which mainly supports users to generate, share, edit, forward and disseminate information on the platform and support instant dialogue between users [12]; the community-creation technical, which is aimed to support members as consumers or sellers can join in a certain community based on their own interests, and once joined, they can communicate with others in the forum section, they can also follow or be followed by others so that they see updated information such as product reviews and favorite items [13]. The three technical features is the core technologies of the social platform, however, there is a lacking of researchers have explored how these technologies affect the users' behavior, especially, the users' intention to continue sharing their generate contents. Therefore, the purpose of this paper is to investigate the influences on users' intention to continue sharing contents form the technical features perspective.

\subsection{Social Cognitive Theory}

Social cognition theory (SCT) was originally proposed by Bandura [4]. The theory emphasized that social environment, individual cognition, and individual behavior are dynamic interactions, and constitute a ternary interaction model, which is the core of social cognition theory. In social cognition theory, social environmental factors are the objective conditions for individuals to behave in different social network situations. Personal cognitive factors are in the form of "cognitive, emotional and biological events". The behavior is the product of the interaction between the self-cognitive system and the social environment. In particular, SCT highlights the important functions of human's cognitive abilities: self-efficacy perception and outcome expectations.

Self-efficacy refers to the ability assessment of an individual's ability to perform an effective behavior, not the same as the individual's actual knowledge 
and ability. It will affect the individual's decision, the behavior, the degree of effort and the control of the behavior. In social commerce platform, the conditions for the sharing of content contributors include the fact that users believe their ability to complete the creation of content, and what the content they share can influence and help others. If users' self-efficacy is insufficient, it is difficult for them to generate and share corresponding contents.

Individual outcome expectation refers to people's judgment of the outcome of their actions. The process of knowledge or experience sharing on the social commerce platform includes such sorting, editing, inputting, etc. This process will take a certain amount of time and effort, which can be regarded as the opportunity cost of users' sharing. Individual is a rational person who pursues interests, behavior will only occur if the benefit of his or her behavior exceeds the cost of his or her contribution [14]. If users believe that one can achieve personal expectation such as others' praise, respect, trust, higher authority, and so on through their content sharing behavior on the social platform, then the behavior will be activated.

\subsection{Intention to Continue Sharing Contents}

Knowledge sharing is a key factor in the development of virtual communities. Different scholars have different definitions of user knowledge sharing in virtual communities. Some scholars believe that continuous knowledge sharing behavior is a simple extension of knowledge sharing behavior, the influence factors are same. Other scholars consider the continuous knowledge sharing behavior as a post-adoption behavior and believe that a different set of determinants is needed to explain the user's continuous sharing behavior. Combined with the research object, this paper believes that on the social commerce platform, users' continuous content sharing refers to users share their information, experience, ideas, answers to others' questions and search, forward, rate others' information, also consulting issues, and the intention to continue this behavior.

Until now, there is a great deal of research has investigated the factors influencing knowledge-sharing behavior in virtual communities from various theoretical perspectives, which can be divided into two categories. One is the Expectation Confirmation Model (ECM-ISC) for the continuous use of information systems and its revolution research model. The model shows that the user's expected confirmation is an important factor on its continuous use, in which perceived usefulness and usage satisfaction mediate [15]. ECM-ISC is a classic model for the continuous use of research, and many studies about this theme are derived from the ECM-ISC model. Another is other theory, for example, Liao used utilitarianism and hedonism as initial variables, knowledge sharing attitude as a mediator to study the relationship between these factors and the continued willingness of users to share [16]. Yang $\mathrm{H}$ explored the content sharing behaviors of young American and Chinese consumers in different cultural contexts based on social capital theory [17]. Social commerce is a new e-commerce plat- 
form with the unique characters of the users' content sharing behavior, whose influence factors are necessary to be investigated.

\section{Research Model and Development of Hypotheses}

According to the research questions, literature review and theoretical basis, the research model is shown in Figure 1. As seen from Figure 1, this paper tries to investigate the role of technical features on the social commerce environment, along with technical features, the researcher added self-efficacy, outcome expectation and the continuous intention to share information or experience as on-going issues in this platform. The details are as follows: users' continuous intention to share as the dependent variable, technical features such as the personalized, interaction, community-creation technical feature as the antecedent variable, and the social cognition self-efficacy, outcome expectation as the mediator variable.

\subsection{Social Commerce Technical Features}

Compared with traditional e-commerce platform, on social commerce platform, users will be provided more feelings of empowerment and enjoyment and be offered more support to co-create, interact and generate content on the internet [18]. The uses of web 2.0 have changed the way users and enterprises interact and collaborate [19]. Also, it enable the social commerce platform has four main unique characteristics: interactivity, collaboration, community and social aspect, those give s-commerce its uniqueness and distinguished it from traditional e-commerce [20] [21]. Based on our review, we conclude the four main uniqueness of social commerce is achieved by three technical features: the personalized technical, the interaction technical and the community-creation technical.

The personalized technical provide more opportunities for user to fulfil their

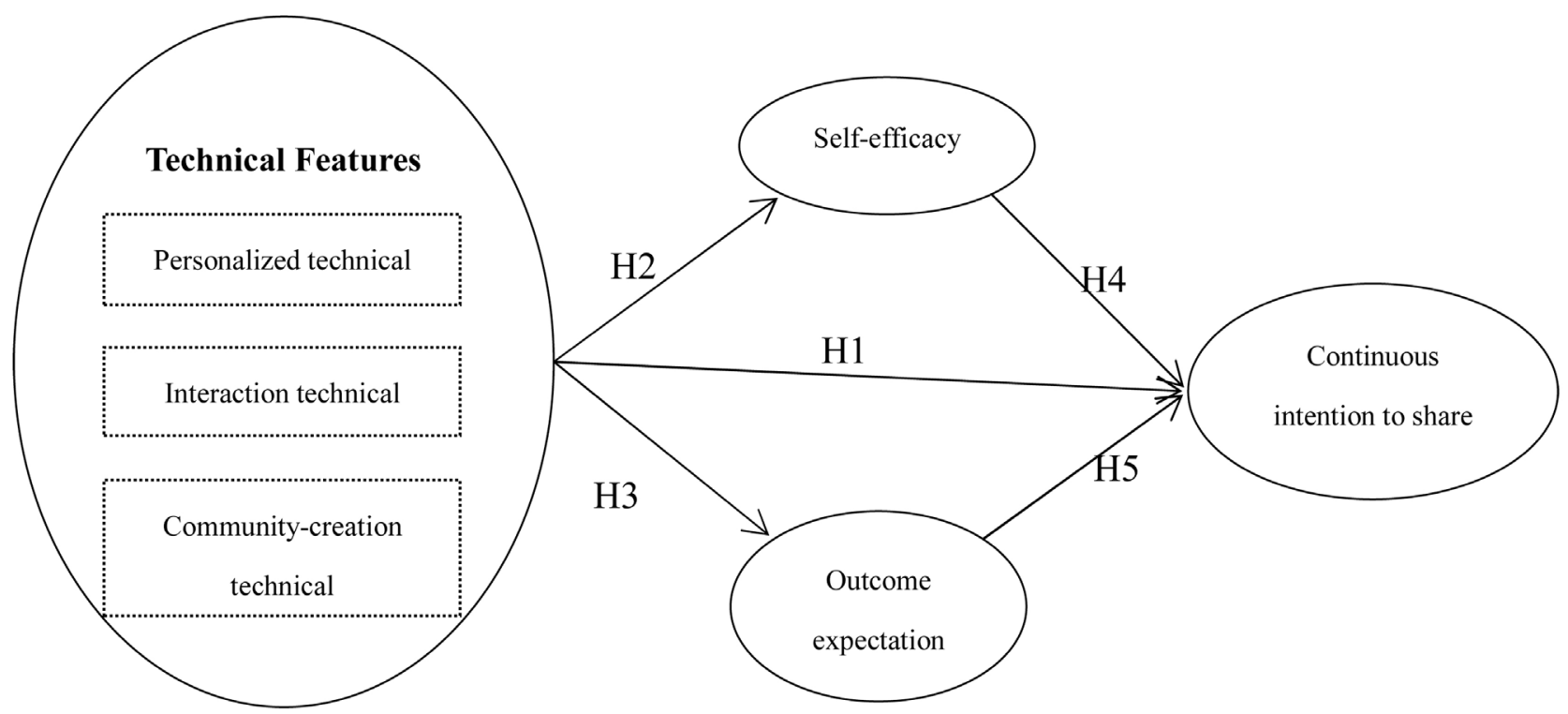

Figure 1. Hypothesized model of continuous intention to share. 
personalized expression, achieve preferred various products or activities information. If the information or activities theme recommended by the platform is compatible with user's interests or demands, the user is more likely to like, comment or forward the recommended contents or share it again after processing. Also, the user is more willing to participate in the discussion about the popular event topics, express their own opinions.

The construction of interaction technical feature in social commerce platform should include message reminder, comment, forwarding, recommendation, etc. The social function is supported by the interaction technical changes the role of the platform user, which not only allows the user to complete the purchase, but also promotes the user's generate content on the platform [22]. And the interaction technical can be used to encourage users to make positive word-of-mouth recommendations [23].

One of the main differences between social commerce and e-commerce is that s-commerce is a community based environment. Because of the use of community-creation technical, members on the social commerce platform can gathered in one certain community to interact with each other. In such a community, sellers want consumers to be brand communicators, while consumers want to make smarter buying decisions, so, all the members will have more motivation to generate or share more contents [24]. Members gather in the certain community may because of their own needs or the value. If individuals feel that they are no longer an independent person but have membership, they are more likely to continue to participate in the community, even form continuous sharing behavior.

Consequently, this study can hypothesize:

H1 Social commerce technical features have a positive effect on the user's continuous intention to share contents.

These three technical features also have influence on self-efficacy. On social commerce platform, for each user, the first step is to create personal home page, including avatars, signatures, descriptions of interest, and other settings. In the process of creating personalized image, the user's evaluation of self-ability will increase if various technical function designs can be quickly perceived and used, thereby enhancing the user's self-efficacy perception. In addition, the personalized technical support will also provide customers with a unique interactive interface and allow customers to change the user interface according to their preferences, thus fully satisfying the individual needs. In turn, encourage users to actively invest more time, energy and money in some customized activities, which will give customers a sense of control over the platform, in turn increases user self-efficacy. And, Bandura A. found that in the process of interaction, person will have a new reassessment of self-efficacy by comparing with the performance about an activity completion of similar individuals [25], particularly, the positive information from peers, experts, and family members by communication will promote individual self-efficacy. Moreover, specialized communities 
can enhance members' sense of belonging and motivate knowledge exchange, every user can learn and accumulate all knowledge what others shared, which will enhance the confidence and ability of users to create and share relevant knowledge, and will also improve the quality of knowledge shared by users. Thus, encouraging the user's self-efficacy.

Consequently, this study can hypothesize:

\section{$\mathrm{H} 2$ Social commerce technical features have a positive effect on the user's} self-efficacy.

And, these there technical features have influence on personal outcome expectation. The personalized technical feature can not only satisfy the user's personal expression, but also satisfying the customer's product information preference, that is personalized recommendation. This technical feature has a positive impact on social support perceived by users [26]. In other words, the personalized technical feature is able to increase the user's value perception of the platform, which in turn improves the user's outcome expectation in socializing, altruistic, expressing themselves and so on. The interaction technical feature will facilitate users to have more communication with others and establish relationships, which will increase the user's emotional dependence on this platform, thus increase their value perception. Also, in the process of the interaction, users can obtain more helpful product information, and then make a more suitable purchase decision. It is not difficult to find users will achieve more benefits because of the interaction technical feature. Also, once the user joined a certain community, he/she will obtain more instant help if he/she cannot make the purchase decision, because in a certain community, users can find others' similar experiences, or send messages for help promptly, then get suggestions from others more quickly. The social support from the community what the user joined the added value of this platform, which can improve the user's outcome expectations after he/she engage to social commerce platform [27].

Consequently, this study can hypothesize:

H3 Social commerce technical features have a positive effect on the user's outcome expectations.

\subsection{Self-Efficacy}

In social cognitive theory, one important cognitive factor is self-efficacy, which is defined as individual belief in the ability to organize and execute the courses of action required to produce given attainments. One's self-efficacy will affect what decisions they make and what behaviors they take, it is the important factors to influence user's content sharing. For example, when user has more confidence to take one behavior on the social commerce platform, he/she is likely to be motivated to take the behavior. In this sense, those who perceive themselves to be highly efficacious with reference to a particular content sharing will be more likely to invest sufficient effort, time and energy to achieve a successful outcomes than those with low levels of self-efficacy. Self-efficacy has been empirically ex- 
amined in relation to the knowledge sharing. Kankanhall found that self-efficacy has a direct positive impact on knowledge sharing behavior when an individual uses an electronic knowledge database [28]. Lin believed that those who are confident in contributing to share organizational knowledge are more likely to show their continuous intention to share knowledge [29].

Consequently, this study can hypothesize:

H4 Self-efficacy has a positive effect on the user's continuous intention to share contents.

\subsection{Outcome Expectation}

Outcome expectation is another cognitive factor in social cognitive theory. It refers to the expected judgment of the individual's result after he or she has made a certain behavior. Outcome expectation is a direct motivation for promoting one's behavior, in particular, many scholars have found that many of the traditional benefits are the primary motivation for consumers engagement with online brand community, for example, strengthening the connection with social friends, seeking social status (such as gaining attention), establishing reputation [30]; and offering help to others will also promote the generation of news [31]. So, if users on social commerce platform have positive outcome expectation in socializing aspects such as establishing contacts, gaining recognition, self-presentation, and altruism through the sharing of content and knowledge, which will strengthen the user's continuous intention to share his/her purchase experience and products knowledge.

Consequently, this study can hypothesize:

H5 Outcome expectation has a positive effect on the user's continuous intention to share contents.

\section{Research Methodology}

To test the research model, the questionnaires were used to collect the observation data in the model, the confirmatory factor analysis was performed on the measurement model, and the structural equation model was used to test the hypothesis. The questionnaire consists of two parts: the demographic characteristics of the respondents and the measures of all factors in the research model.

\subsection{Measurement Development}

The research has six constructs, the questionnaire including the operational definition of the variable measurement was developed by the scales constructed and tested by the predecessors in the existing literature. The research used a seven point Likert-scale from 1, strongly disagree to 7 , strongly agree. Personalized technical feature measures the level of support for the users' personalized expression and the satisfaction level of individual needs on the social commerce platforms [32]. Interaction technical feature measures the level of satisfaction of effective communication needs between users [33]. Community-creation technical measures the level of support for the users to create one certain community 
[7]. Self-efficacy perception was measured by the individual's ability to control himself, to provide information knowledge, and the perception of his own power [34]. Outcome expectation measures the individual's social, altruistic outcome expectations, the level of support of the self-expression, and the feedback and interaction from other people [35]. The dependent variable of this research is continuous intention to share. Continuous intention to share measures the user's willingness to pay on social commerce platform and their intention to share purchase experience or product information through social commerce platform [36].

\subsection{Data Collection}

According to the purpose of this paper, we targeted users of Red, which is a kind of social commerce platform with shopping experience sharing community and cross-border e-commerce. Before the formal survey, a sample test with 20 students was used to make sure the questions and wordings were clearly understood by respondents. The questionnaire was in paper and electronic version to maximize the number of participants. Finally, 360 responses were received, there were 356 valid questionnaires, yielding a response rate of 97.8 percent, some of the questionnaires were dropped as they were incomplete, clearly regular, and the answer time less than 1 minute. Most of the respondents are female (70.8\%), belonging the age group between 18 and 30 years (94.4\%). Most of them are with high educational level, and the usage frequency per week less than 2 times, the use time less 30 minutes. Table 1 shows the demographic information of the respondents.

\subsection{Data Analysis Technique}

A two-stage analytical procedure was used to analyze the data. First, we examined the reality and validity of the measurements, and then examined its structure model. Structural Equation Modelling (SEM) was applied in this paper. SEM as recommended has many advantages over other methods. This paper chose Analysis of Moment Structure (AMOS) method to test the hypotheses. AMOS is able to provide more accurate and comprehensive analysis results compared with factor analysis or regression analysis. Also it can provide a graphical environment for each step in the process of constructing an equation model, and can test the relationship between variables through rapid model establishment. The validity and reliability of constructs can be assessed simultaneously through AMOS method [37]. According to the sample size and the research question, model, AMOS was used to conduct the data analysis.

\section{Data Analysis}

\subsection{Reliability and Validity Analysis}

\subsubsection{Reliability}

The reliability refers to the internal consistency of the measurement. The purpose 
Table 1. Demographic information of the respondents.

\begin{tabular}{|c|c|c|c|}
\hline Dimension & Category & Frequency & Percentage \\
\hline \multirow{2}{*}{ Gender } & Male & 104 & $29.2 \%$ \\
\hline & Female & 252 & $70.8 \%$ \\
\hline \multirow{7}{*}{ Age } & Under 18 & 3 & $0.8 \%$ \\
\hline & $18-25$ & 215 & $60.4 \%$ \\
\hline & $26-30$ & 121 & $34.0 \%$ \\
\hline & $31-40$ & 15 & $4.2 \%$ \\
\hline & $41-50$ & 2 & $0.6 \%$ \\
\hline & $51-60$ & 0 & 0 \\
\hline & Over 61 & 0 & 0 \\
\hline \multirow{4}{*}{ Education } & Senior high school & 25 & $7.0 \%$ \\
\hline & Junior college & 24 & $6.7 \%$ \\
\hline & Bachelor's degree & 172 & $48.3 \%$ \\
\hline & Master's degree or above & 135 & $37.9 \%$ \\
\hline \multirow{6}{*}{ Occupation } & Students & 127 & $35.7 \%$ \\
\hline & Workers & 142 & $39.9 \%$ \\
\hline & Civil servants & 42 & $11.8 \%$ \\
\hline & Private owners & 13 & $3.7 \%$ \\
\hline & Retirees & 2 & $0.6 \%$ \\
\hline & Others & 30 & $8.4 \%$ \\
\hline \multirow{6}{*}{$\begin{array}{l}\text { Average monthly } \\
\text { income }\end{array}$} & Under 1000 & 88 & $24.7 \%$ \\
\hline & $1000-3000$ & 62 & $17.4 \%$ \\
\hline & $3001-5000$ & 74 & $20.8 \%$ \\
\hline & $5001-7000$ & 61 & $17.1 \%$ \\
\hline & $7001-10,000$ & 46 & $12.9 \%$ \\
\hline & Over 10,000 & 25 & $7.0 \%$ \\
\hline \multirow{4}{*}{$\begin{array}{l}\text { Weekly usage } \\
\text { frequency }\end{array}$} & Under 2 times & 252 & $70.8 \%$ \\
\hline & $2-4$ times & 58 & $16.3 \%$ \\
\hline & $5-7$ times & 25 & $7.0 \%$ \\
\hline & Over 7 times & 21 & $5.9 \%$ \\
\hline \multirow{4}{*}{ Usage time per use } & Less $10 \mathrm{~min}$ & 182 & $51.1 \%$ \\
\hline & $10-30$ & 139 & $39.0 \%$ \\
\hline & $31-60$ & 28 & $7.9 \%$ \\
\hline & Over 60 & 7 & $2.0 \%$ \\
\hline
\end{tabular}

of the reliability test is to verify the consistency and stability of the measurement scale indicators, so as to obtain the reliability of the scale indicators. There are different methods available to test the internal consistency. The composite reliability (CR) and Cronbach's alpha were chosen to interpret the reliability in this research. Their accepted value should exceed 0.70 , the result as seen in Table 2 . All constructs have a value more than 0.70 , an acceptable value for this 
Table 2. Sources of constructs, reliability and validity.

\begin{tabular}{|c|c|c|c|c|}
\hline Codes & Scales & CR & AVE & $\begin{array}{l}\text { Cronbach's } \\
\text { alpha }\end{array}$ \\
\hline & Personalized technical (Adapted from Kumar N) & & & \\
\hline PER1 & My individual needs can be meet completely on the Red. & & & \\
\hline PER2 & $\begin{array}{l}\text { The targeted recommendations can be provided } \\
\text { based on my needs on the Red. }\end{array}$ & 0.850 & 0.655 & 0.849 \\
\hline PER3 & $\begin{array}{l}\text { Extra services and information can be supported } \\
\text { based on my preferences on the Red. }\end{array}$ & & & \\
\hline & Interaction technical (Adapted from Nambisan). & & & \\
\hline INT1 & Red supports to instant notice once I received messages. & & & \\
\hline INT2 & $\begin{array}{l}\text { Red allows me to send messages in different } \\
\text { formats such as text, photos, videos etc. }\end{array}$ & 0.883 & 0.653 & 0.882 \\
\hline INT3 & $\begin{array}{l}\text { Red allows me to create conversations around } \\
\text { one certain topic with others. }\end{array}$ & & & \\
\hline INT4 & $\begin{array}{l}\text { Red allows me to like, comment, and } \\
\text { forward other users' shared-content. }\end{array}$ & & & \\
\hline
\end{tabular}

COM1 Red allows me to create small communities based on my interests.

COM2

Red allows the community member provide timely advice when someone need help.

COM4

Red will remind me of the latest activities from the small community.

Self-efficacy (Adapted from Oeldorf-Hirsch).

I believe that the content I share can attract the attention of others on Red.

SEL2 I believe I can provide valuable content to others on Red.

I think the content I share can influence the thoughts of others on Red.

Outcome expectation (Adapted from Kim \& Lee). I sharing information on Red.

OUT2 It will strengthen me to contact with others when I sharing information on Red.

OUT3 It will provide help to others when I sharing information on Red.

OUT4 I can obtain some rewards when I sharing information on Red.

Continuous intention to share (Adapted from Zheng).

CON1 In the future, I prefer to share my shopping experience on Red.

CON2 In the future, I would rather recommend my favorite products on Red. and type of contents I share on Red. 
test, it shows each measurement item has good internal consistency. The data accurately for the survey is ensured by these two types of reliability tests.

\subsubsection{Validity}

Validity test including content and construct validity test. To ensure the effectiveness of the content validity, the author read and review a lot of relevant literature in the area of e-commerce and social commerce, then chose the existing mature scale to ensure the representative and completeness of the scale, which demonstrate the content validity of the measurement scale in this paper meets the requirements of scientific research. The literature source for each construct, which has been used in the literature review, is shown in Table 1.

Construct validity includes two aspects: convergence validity and discriminant validity. The convergence validity refers to the test indicators that measure the same potential traits (constructs) will fall on the same factor. Average Variance Extracted (AVE) has been chosen to examine the convergence validity, the results as shown in Table 2, where AVE in all constructs is more than 0.5 indicating that this research achieved these criteria.

Discriminant validity refers to measure the extent to which a given construct of the research model is different from others [37]. It is generally required that the square root of the latent variable AVE is greater than the correlation coefficient of all other latent variables. As seen Table 3, all AVEs are greater and demonstrate discriminant validity.

Another way to assess discriminant and convergent validity of the research is by examining the factors loading of each indicator. The result shown in Table 4, the factors loading for each construct and confirms that the observed indicators has enough convergent and discriminant validity.

\subsection{The Results of Structural Model}

The estimation results from AMOS software are shown in Figure 2. According to the results, all the paths among constructs are positive and significant at the 0.05 level. The model validity is assessed by $\mathrm{R}$ square value and the structural paths [38]. The results of the $\mathrm{R}$ square indicate that almost $85.7 \%$ of the variance in the continuous intention to share was accounted for by technical features,

Table 3. Square of correlation between constructs.

\begin{tabular}{|c|c|c|c|c|c|c|}
\hline & $\begin{array}{l}\text { Interaction } \\
\text { technical }\end{array}$ & $\begin{array}{c}\text { Community-creation } \\
\text { technical }\end{array}$ & $\begin{array}{l}\text { Personalized } \\
\text { technical }\end{array}$ & $\begin{array}{l}\text { Outcome } \\
\text { expectation }\end{array}$ & Self-efficacy & $\begin{array}{c}\text { Continuous intention } \\
\text { to share }\end{array}$ \\
\hline Interaction technical & 0.808 & & & & & \\
\hline Community-creation technical & 0.167 & 0.790 & & & & \\
\hline Personalized technical & 0.343 & 0.130 & 0.809 & & & \\
\hline Outcome expectation & 0.281 & 0.184 & 0.321 & 0.781 & & \\
\hline Self-efficacy & 0.303 & 0.308 & 0.300 & 0.165 & 0.791 & \\
\hline Continuous intention to share & 0.670 & 0.527 & 0.655 & 0.490 & 0.545 & 0.899 \\
\hline
\end{tabular}


Table 4. Item loading and cross-loading.

\begin{tabular}{|c|c|c|c|c|c|c|}
\hline & $\begin{array}{c}\text { Interaction } \\
\text { technical }\end{array}$ & $\begin{array}{c}\text { Community-creation } \\
\text { technical }\end{array}$ & $\begin{array}{l}\text { Outcome } \\
\text { expectation }\end{array}$ & $\begin{array}{c}\text { Personalized } \\
\text { technical }\end{array}$ & Self-efficacy & $\begin{array}{c}\text { Continuous intention } \\
\text { to share }\end{array}$ \\
\hline PER1 & 0.143 & 0.003 & 0.079 & 0.856 & 0.080 & 0.004 \\
\hline PER2 & 0.158 & 0.076 & 0.127 & 0.811 & 0.108 & 0.018 \\
\hline PER3 & 0.068 & 0.003 & 0.120 & 0.863 & 0.066 & 0.132 \\
\hline INT1 & 0.842 & 0.031 & 0.100 & 0.048 & 0.108 & 0.026 \\
\hline INT2 & 0.842 & 0.038 & 0.067 & 0.116 & 0.068 & 0.105 \\
\hline INT3 & 0.841 & 0.014 & 0.089 & 0.109 & 0.131 & 0.126 \\
\hline INT4 & 0.824 & 0.099 & 0.078 & 0.163 & 0.011 & 0.027 \\
\hline COM1 & 0.068 & 0.761 & 0.123 & 0.038 & 0.046 & 0.062 \\
\hline $\mathrm{COM} 2$ & 0.081 & 0.840 & 0.036 & 0.004 & 0.127 & 0.106 \\
\hline COM3 & 0.065 & 0.876 & 0.039 & 0.040 & 0.092 & 0.073 \\
\hline COM4 & 0.011 & 0.840 & 0.020 & 0.081 & 0.094 & 0.049 \\
\hline SEL1 & 0.092 & 0.172 & 0.026 & 0.134 & 0.826 & 0.173 \\
\hline SEL2 & 0.152 & 0.107 & 0.088 & 0.085 & 0.848 & 0.036 \\
\hline SEL3 & 0.084 & 0.069 & 0.105 & 0.096 & 0.835 & 0.051 \\
\hline OUT1 & 0.097 & 0.112 & 0.834 & 0.096 & 0.033 & 0.132 \\
\hline OUT2 & 0.132 & 0.007 & 0.819 & 0.087 & 0.073 & 0.039 \\
\hline OUT3 & 0.055 & 0.058 & 0.806 & 0.183 & 0.028 & 0.123 \\
\hline OUT4 & 0.108 & 0.078 & 0.825 & 0.066 & 0.215 & 0.074 \\
\hline CON1 & 0.149 & 0.079 & 0.050 & 0.093 & 0.172 & 0.803 \\
\hline CON2 & 0.056 & 0.177 & 0.079 & 0.058 & 0.344 & 0.769 \\
\hline CON3 & 0.090 & 0.092 & 0.178 & 0.074 & 0.096 & 0.856 \\
\hline
\end{tabular}

self-efficacy and outcome expectation. It means continuous intention to share was, as hypothesized, influenced by technical features, self-efficacy and outcome expectation. The R square for self-efficacy means that $19.5 \%$ of the variance in this construct was accounted for by technical features, and for outcome expectation means that $15.1 \%$ of the variance in this construct was accounted for by technical features. Thereby, the result of $\mathrm{R}$ square shows a satisfactory level of explanation. In the next section, the relationships among these constructs are explained and interpreted. In addition, directed effects of technical features, self-efficacy, outcome expectation and continuous intention to share are examined.

As shown in Figure 2, the results of each hypothesis are as follows: Hypothesis 1 posits that technical features influence the continuous intention to share. From Figure 2, it can be observed that the path coefficient between personalized technical, interaction technical, community-creation technical and continuous intention to share is $0.369(\mathrm{P}<0.001), 0.383(\mathrm{P}<0.001), 0.325(\mathrm{P}<0.001)$, thus supporting Hypothesis 1 . Hypothesis 2 shows that the path coefficient between personalized technical, interaction technical, community-creation technical and self-efficacy is $0.201(\mathrm{P}<0.01), 0.192(\mathrm{P}<0.01), 0.249(\mathrm{P}<0.001)$, so hypothesis 


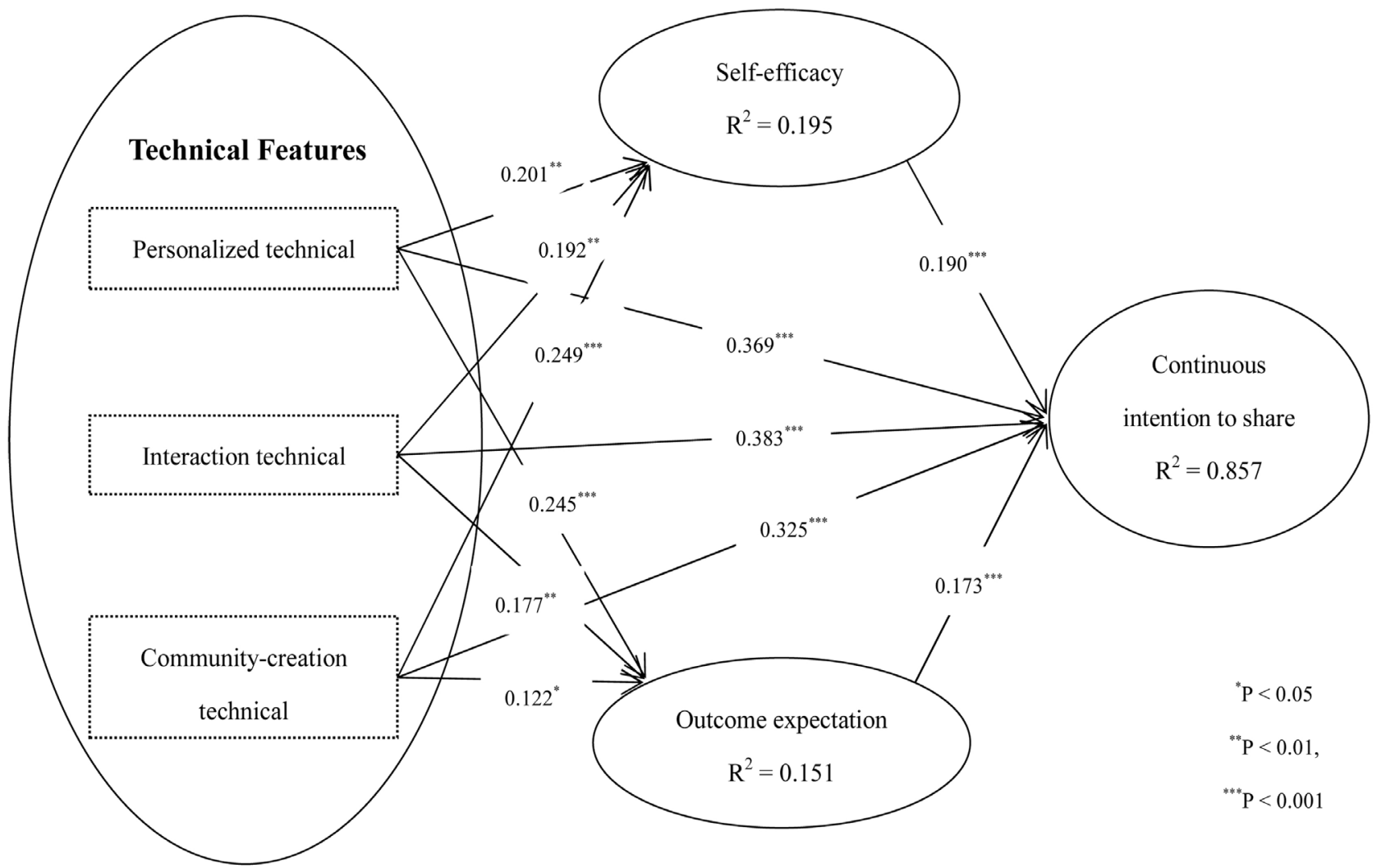

Figure 2. Results of AMOS analysis.

2 is also confirmed. For hypothesis 3, the path coefficient between personalized technical, interaction technical, community-creation technical and outcome expectation is 0.245 ( $\mathrm{P}<0.001), 0.177(\mathrm{P}<0.01), 0.122(\mathrm{P}<0.05)$, so the hypothesis 3 is confirmed. The positive effect of self-efficacy on the continuous intention to share is also supported $(\beta=0.19, \mathrm{P}<0.001)$, thereby confirming Hypothesis 4 . And the positive effect of outcome expectation on the continuous intention to share is confirmed $(\beta=0.173, \mathrm{P}<0.001)$, thus supporting the Hypothesis 5 .

We also tested the mediation effect of self-efficacy and outcome exception between technical features and continuous intention to share. Although most of researchers used the causal regression method to test the mediation effect, some scholars have questioned the validity and rationality of the method in recent years, and recommend using the Bootstrapping method for mediation effect analysis to solve the significant failure caused by the non-normal distribution of mediation effects, and the non-parametric percentile Bootstrapping method commonly used by scholars. Thereby, the bias-corrected non-parametric percentile Bootstrapping method was used to test the mediation effect in this paper. If the $95 \%$ confidence interval of the indirect effect does not contain 0 , the mediation effect is significant; when 0 is included, the mediation effect is not significant, the results of the mediation effect as shown in Table 5. As seen in Table 5, the mediation effect of self-efficacy and outcome exception between technical features and continuous intention to share is supported. 
Table 5. The results of the mediation effect test.

\begin{tabular}{ccc}
\hline Mediation path & $\begin{array}{c}\text { Indirect effect estimation of normalization } \\
\text { coefficients }\end{array}$ & $\begin{array}{c}95 \% \text { confidence } \\
\text { interval }\end{array}$ \\
\hline PER $\rightarrow$ SEL $->$ CON & $0.201^{\star} 0.190=0.038$ & {$[0.028,0.111]$} \\
PER $>$ OUT $>$ CON & $0.245^{\star} 0.173=0.042$ & {$[0.019,0.083]$} \\
INT $\rightarrow$ SEL $>$ CON & $0.192^{\star} 0.190=0.036$ & {$[0.017,0.107]$} \\
INT $>$ OUT $>$ CON & $0.177^{\star} 0.173=0.031$ & {$[0.012,0.068]$} \\
COM $\rightarrow$ SEL $>$ CON & $0.249^{\star} 0.190=0.047$ & {$[0.037,0.146]$} \\
COM $>$ OUT $\rightarrow>C O N$ & $0.122^{\star} 0.173=0.021$ & {$[0.001,0.050]$} \\
\hline
\end{tabular}

\section{Discussion}

The research model of this paper has been developed to explore the role of technical features, user's self-efficacy and outcome expectation on the user's continuous intention to share in the social commerce era. The results of this study show that technical features of the social commerce platform have significant positive effect on users' self-efficacy, personal outcome expectation and the continuous intention to share their knowledge, information, and experiences about a product or a service with their peers, also the self-efficacy and outcome expectation have partially mediation effect between technical features and continuous intention to share. In the social commerce platform, the technical features like the personalized technical, the interaction technical and the community-creation technical provide more opportunities for users to have a freedom personal self-expression, seek more preferable information at the lower time cost, make a instant and effective conversation with others and find more friends with similar interest more easily. Initially, the user's self-efficacy and personal outcome expectation will be strengthened, they will be with higher level of self-efficacy and outcome expectation in the platform, and then, they will increase their intention to enjoy participation in creating and sharing content. Overall, this research indicates that the technical features of the social commerce are more likely to attract individuals, increase their self-efficacy, outcome expectation and influence users' continuous intention to share.

\subsection{Theoretical and Practical Contribution of This Research}

For the theoretical contribution, this study makes several important contributions to the study of users behavior in the social commerce platform. First, this paper explores the influence factors on the continuous intention to share enrich the research content. In this field of social commerce, the present researchers have paid most attention to explore the influence factors on the intention to buy or purchase behavior, they neglected users' content sharing is the key to leading their willingness to purchase and the basis for interaction and stickiness of other users on the platform. Second, this paper provides a new research perspective-technical feature. Social commerce construed based on advanced web 2.0 technologies and social media technologies, which enable users to be more active 
on this platform compared with on the traditional e-commerce. This paper finds the main cause from technical features perspective, the result of this study shows the personalized, interaction and community-creation technical feature have a positive influence on users' intention to share. Third, this paper also finds the technical features will increase users' self-efficacy, outcome expectation, which in turn increases users' intention to share.

In terms of the practical contribution, the present research highlights the role of social commerce technical features and how they shape social commerce and increase the level of self-efficacy, personal outcome expectation and continuous intention to share. The results give some practical instructions to the e-commerce platform operator as to how social commerce technical features can be used as user's self-efficacy and personal outcome expectation building mechanisms to influence consumer behaviour and continuous intention to generate and share content on the platform. So, the platform operator can optimize the the platform from the three aspects as follows. First, the platform operator should strengthen the use of personalized technical to provide users with friendly function of the self-presentation and personalized recommendations, such as enhancing the comfort, aesthetics and ease of operation of web pages, organizing various exhibition activities, such as beauty exhibitions, food exhibitions, etc to stimulate users to share. Second, the platform operator should enrich the form of the interaction technical, such as adding the functions to exchange gift cards, share points, and reward favorite content. Third, the platform operator should improve the process for users to use community creation technology, such as setting the conditions for the community manager, rewarding the active community.

\subsection{Limitations and Future Research}

The research is not without limitation. One of the research limitations is that the study did not consider these factors have different influences on different users. The future research can study the factors affecting users' continued willingness to share based on different types of users, which can be classified as core users, regular users, browsing users. And another limitation is that the theoretical research model is developed trough the previous research, not trough the interviews. Therefore, future research can combine qualitative and quantitative research methods to explore the influencing factors of users' continued willingness to share, and obtain more practical management implications.

\subsection{Conclusion}

In this paper, we developed and examined a theoretical model that explains users' continuous intention to share in a social commerce platform by focusing on the individual cognition-self-efficacy and outcome expectation from technical features perspective. By combining the technical literature, social cognition theory with the social commerce literature, we found that self-efficacy and out- 
come expectation had a significant influence on the degree of continuous intention to share content, and that technical features had both a direct and indirect influence on the degree of continuous intention to share content through its impact on self-efficacy and outcome expectation. Thus, this study demonstrates the importance of technical features and personal cognition in determining the level of continuous intention to share knowledge in social commerce platform.

\section{Conflicts of Interest}

The authors declare no conflicts of interest regarding the publication of this paper.

\section{Fund Project}

National Natural Science Foundation of China: Research on the Mechanism of Online Symbolic Action to Consumer Drift (71761003).

\section{References}

[1] Nielsen, J. (2006) Participation Inequality: Lurkers vs. Contributors in Internet Communities. Jakob Nielsen's, Alertbox.

[2] Chiou, L. and Tucker, C. (2017) Content Aggregation by Platforms: The Case of the News Media. Journal of Economics \& Management Strategy, 26, 782-805. https://doi.org/10.1111/jems.12207

[3] Hajli, M. (2013) A Research Framework for Social Commerce Adoption. Information Management \& Computer Security, 21, 144-154. https://doi.org/10.1108/IMCS-04-2012-0024

[4] Bandura, A. (2001) Social Cognitive Theory: An Agentic Perspective. Annual Review of Psychology, 52, 1-26. https://doi.org/10.1146/annurev.psych.52.1.1

[5] Jascanu, N., Jascanu, V. and Nicolau, F. (2007) A New Approach to E-Commerce Multi-Agent Systems.

[6] Ghose, A. and Ipeirotis, P. (2009) The EconoMining Project at NYU: Studying the Economic Value of User-Generated Content on the Internet. Journal of Revenue and Pricing Management, 8, 241-246. https://doi.org/10.1057/rpm.2008.56

[7] Hajli, N. (2015) Social Commerce Constructs and Consumer's Intention to Buy. International Journal of Information Management, 35, 183-191. https://doi.org/10.1016/j.ijinfomgt.2014.12.005

[8] Bai, Y., Yao, Z. and Dou, Y. (2015) Effect of Social Commerce Factors on User Purchase Behavior: An Empirical Investigation from renren.com. International Journal of Information Management, 35, 538-550. https://doi.org/10.1016/j.ijinfomgt.2015.04.011

[9] Hasanov, J. and Khalid, H. (2015) The Impact of Website Quality on Online Purchase Intention of Organic Food in Malaysia: A WebQual Model Approach. Procedia Computer Science, 72, 382-389. https://doi.org/10.1016/j.procs.2015.12.153

[10] Crossler, R.E., Long, J.H., Loraas, T.M. and Trinkle, B.S. (2014) Understanding Compliance with Bring Your Own Device Policies Utilizing Protection Motivation Theory: Bridging the intention-Behavior Gap. Journal of Information Systems, 28, 209-226. https://doi.org/10.2308/isys-50704

[11] Constantinides, E. and Fountain, S.J. (2008) Web 2.0: Conceptual Foundations and 
Marketing Issues. Journal of Direct, Data and Digital Marketing Practice, 9, 231-244. https://doi.org/10.1057/palgrave.dddmp.4350098

[12] Han, Y.S., Choi, J.K. and Ji, Y.G. (2011) A Study on Social Network Services Visualization Based on User Needs. Springer, Berlin/Heidelberg, 319-325.

[13] Xiao, B., Huang, M. and Barnes, A.J. (2015) Network Closure among Sellers and Buyers in Social Commerce Community. Electronic Commerce Research and Applications, 14, 641-653. https://doi.org/10.1016/j.elerap.2015.10.001

[14] Constant, D., Sproull, L. and Kiesler, S. (1996) The Kindness of Strangers: The Usefulness of Electronic Weak Ties for Technical Advice. Organization Science, 7, 119-135. https://doi.org/10.1287/orsc.7.2.119

[15] Bhattacherjee, A. (2001) Understanding Information Systems Continuance: An Expectation-Confirmation Model. MIS Quarterly, 25, 351-370. https://doi.org/10.2307/3250921

[16] Liao, C., To, P. and Hsu, F. (2013) Exploring Knowledge Sharing in Virtual Communities. Online Information Review, 37, 891-909. https://doi.org/10.1108/OIR-11-2012-0196

[17] Yang, H. (2013) A Cross-Cultural Study of Market Mavenism in Social Media: Exploring Young American and Chinese Consumers' Viral Marketing Attitudes, eWOM Motives and Behaviour. International Journal of Internet Marketing and Advertising, 8, 102-124. https://doi.org/10.1504/IJIMA.2013.058596

[18] Füller, J., MüHlbacher, H., Matzler, K. and Jawecki, G. (2009) Consumer Empowerment through Internet-Based Co-Creation. Journal of Management Information Systems, 26, 71-102. https://doi.org/10.2753/MIS0742-1222260303

[19] Jiang, G., Ma, F., Shang, J. and Chau, P.Y. (2014) Evolution of Knowledge Sharing Behavior in Social Commerce: An Agent-Based Computational Approach. Inform Sciences, 278, 250-266. https://doi.org/10.1016/j.ins.2014.03.051

[20] Kim, S. and Park, H. (2013) Effects of Various Characteristics of Social Commerce (s-Commerce) on Consumers' Trust and Trust Performance. International Journal of Information Management, 33, 318-332.

[21] Busalim, A.H. (2016) Understanding Social Commerce: A Systematic Literature Review and Directions for Further Research. International Journal of Information Management, 36, 1075-1088. https://doi.org/10.1016/j.ijinfomgt.2016.06.005

[22] Blasco-Arcas, L., Buil, I., Hernández-Ortega, B. and Sese, F.J. (2013) Using Clickers in Class. The Role of Interactivity, Active Collaborative Learning and Engagement in Learning Performance. Computers \& Educationm, 62, 102-110. https://doi.org/10.1016/j.compedu.2012.10.019

[23] Shi, S. and Chow, W.S. (2015) Trust Development and Transfer in Social Commerce: Prior Experience as Moderator. Industrial Management \& Data Systems, 115, 1182-1203. https://doi.org/10.1108/IMDS-01-2015-0019

[24] Ng, C.S. (2012) Examining the Cultural Difference in the Intention to Purchase in Social Commerce. 163.

[25] Bandura, A. (1986) Social Foundations of Thought and Action. Prentice-Hall, Englewood Cliffs.

[26] Zhang, H., Lu, Y., Gupta, S. and Gao, P. (2015) Understanding Group-Buying Websites Continuance: An Extension of Expectation Confirmation Model. Internet Research, 25, 767-793. https://doi.org/10.1108/IntR-05-2014-0127

[27] Hajli, M.N. (2014) Social Commerce for Innovation. International Journal of Innovation Management, 18, 1-24. https://doi.org/10.1142/S1363919614500248 
[28] Kankanhalli, A., Tan, B.C. and Wei, K. (2005) Contributing Knowledge to Electronic Knowledge Repositories: An Empirical Investigation. MIS Quarterly, 29, 113-143. https://doi.org/10.2307/25148670

[29] Lin, H. (2007) Knowledge Sharing and Firm Innovation Capability: An Empirical Study. International Journal of Manpower, 28, 315-332. https://doi.org/10.1108/01437720710755272

[30] Lee, C.S. and Ma, L. (2012) News Sharing in Social Media: The Effect of Gratifications and Prior Experience. Computers in Human Behavior, 28, 331-339. https://doi.org/10.1016/j.chb.2011.10.002

[31] Holton, A.E., Baek, K., Coddington, M. and Yaschur, C. (2014) Seeking and Sharing: Motivations for Linking on Twitter. Communication Research Reports, 31, 33-40. https://doi.org/10.1080/08824096.2013.843165

[32] Kumar, N. and Benbasat, I. (2006) Research Note: The Influence of Recommendations and Consumer Reviews on Evaluations of Websites. Information Systems Research, 17, 425-439. https://doi.org/10.1287/isre.1060.0107

[33] Nambisan, S. and Baron, R.A. (2009) Virtual Customer Environments: Testing a Model of Voluntary Participation in Value Co-Creation Activities. Journal of Product Innovation Management, 26, 388-406. https://doi.org/10.1111/j.1540-5885.2009.00667.x

[34] Oeldorf-Hirsch, A. and Sundar, S.S. (2015) Posting, Commenting, and Tagging: Effects of Sharing News Stories on Facebook. Computers in Human Behavior, 44, 240-249. https://doi.org/10.1016/j.chb.2014.11.024

[35] Kim, J., Lee, C. and Elias, T. (2015) Factors Affecting Information Sharing in Social Networking Sites amongst University Students: Application of the Knowledge-Sharing Model to Social Networking Sites. Online Information Review, 39, 290-309. https://doi.org/10.1108/OIR-01-2015-0022

[36] Zheng, X., Zhu, S. and Lin, Z. (2013) Capturing the Essence of Word-of-Mouth for Social Commerce: Assessing the Quality of Online e-Commerce Reviews by a Semi-Supervised Approach. Decision Support Systems, 56, 211-222. https://doi.org/10.1016/j.dss.2013.06.002

[37] Wasko, M.M. and Faraj, S. (2005) Why Should I Share? Examining Social Capital and Knowledge Contribution in Electronic Networks of Practice. MIS Quarterly, 29, 35-57. https://doi.org/10.2307/25148667

[38] Chwelos, P., Benbasat, I. and Dexter, A.S. (2001) Empirical Test of an EDI Adoption Model. Information Systems Research, 12, 304-321.

https://doi.org/10.1287/isre.12.3.304.9708 